\title{
Activating lattice oxygen redox reactions in metal oxides to catalyse oxygen evolution
}

\author{
Alexis Grimaud ${ }^{1 \%} \%$ Oscar Diaz-Morales $2 *$ Binghong Han ${ }^{3}$, Wesley T. Hong ${ }^{3}$, Yueh-Lin Lee ${ }^{1,4}$, \\ Livia Giordano ${ }^{4,5}$, Kelsey A. Stoerzinger ${ }^{3}$, Marc T. M. Koper ${ }^{2}$ and Yang Shao-Horn ${ }^{1,3,4 \star}$
}

\begin{abstract}
Understanding how materials that catalyse the oxygen evolution reaction (OER) function is essential for the development of efficient energy-storage technologies. The traditional understanding of the OER mechanism on metal oxides involves four concerted proton-electron transfer steps on metal-ion centres at their surface and product oxygen molecules derived from water. Here, using in situ ${ }^{18} \mathrm{O}$ isotope labelling mass spectrometry, we provide direct experimental evidence that the $\mathrm{O}_{2}$ generated during the OER on some highly active oxides can come from lattice oxygen. The oxides capable of latticeoxygen oxidation also exhibit pH-dependent OER activity on the reversible hydrogen electrode scale, indicating nonconcerted proton-electron transfers in the OER mechanism. Based on our experimental data and density functional theory calculations, we discuss mechanisms that are fundamentally different from the conventional scheme and show that increasing the covalency of metal-oxygen bonds is critical to trigger lattice-oxygen oxidation and enable non-concerted proton-electron transfers during OER.
\end{abstract}

$\Lambda$ ctivating the anionic redox chemistry of oxygen in metal oxides, on the surface and in bulk, can provide exciting opportunities for the design of materials in clean-energy and environmental applications. Such chemistry, which involves the formation of bulk peroxo-like $\left(\mathrm{O}_{2}\right)^{n-}$ species $^{1}$, has been shown to be important in applications such as catalysing the oxygen evolution reaction (OER) in photoelectrochemical water splitting $^{2-6}$, regenerative fuel cells ${ }^{7,8}$, rechargeable metal-air batteries and storing energy in lithium-ion battery materials ${ }^{9,10}$. In this Article we demonstrate that enabling the oxidation of lattice oxygen in highly covalent metal oxides during the OER can enhance OER activity and trigger non-concerted protonelectron transfer.

The current understanding of the OER mechanism on metal oxides $^{11,12}$, which is largely drawn from studies on metal surfaces ${ }^{13}$, involves four concerted proton-electron transfer steps on surface metal-ion centres, yielding $\mathrm{pH}$-independent activity on the reversible hydrogen electrode (RHE) scale ${ }^{14}$. With this mechanism, high OER activities can be obtained by optimizing the binding strength of reaction intermediates on surfaces (neither too strong nor too weak $)^{11,12}$, and this is supported by experimental findings that the OER activities of oxides in basic solution (the $\mathrm{O}_{2} / \mathrm{H}_{2} \mathrm{O}$ couple: $4 \mathrm{OH}^{-} \rightarrow \mathrm{O}_{2}+2 \mathrm{H}_{2} \mathrm{O}+4 \mathrm{e}^{-}$) correlate with oxide electronic structure parameters such as the estimated $e_{\mathrm{g}}$ occupancy of surface transitionmetal ions ${ }^{15}$. However, this conventional mechanism-centred on the redox chemistry of the metal cation-has been challenged by a few observations in recent years. First, some highly active oxides exhibit pH-dependent OER activity on the RHE scale ${ }^{16-18}$, suggesting that non-concerted proton-electron transfers participate in catalysing the $\mathrm{OER}^{14}$. Second, changing the bulk oxide electronic structure, for example, increasing the oxygen $2 p$-band centre (defined relative to the Fermi level $)^{19,20}$ and metal-oxygen hybridization ${ }^{15,21}$, has been correlated with enhanced OER activities in perovskites, highlighting the role of bulk electronic structure in catalysing OER kinetics ${ }^{19,22,23}$. Third, mass spectrometry measurements of oxides stable in bulk during OER, such as $\mathrm{NiCo}_{2} \mathrm{O}_{4}$ in basic solution ${ }^{24}, \mathrm{IrO}_{2}$ (ref. 25) and $\mathrm{RuO}_{2}$ (ref. 26,27) in acid, and Co-Pi (ref. 28) in neutral solutions, reveal that the evolved oxygen molecules can come not only from water molecules but also from the oxide ${ }^{29-31}$.

In this study, we provide, for the first time, direct experimental evidence for the involvement of lattice oxygen redox chemistry in the OER mechanisms within the perovskite family. On-line electrochemical mass spectrometry (OLEMS) measurements of ${ }^{18} \mathrm{O}$-labelled perovskites reveal that the oxidation of lattice oxygen occurs during the OER for highly covalent oxides such as $\mathrm{La}_{0.5} \mathrm{Sr}_{0.5} \mathrm{CoO}_{3-\delta}$ and $\mathrm{SrCoO}_{3-\delta}$, for which up to 37 monolayers of oxides $(\sim 14 \mathrm{~nm})$ can be involved during the OER process, but not for the less covalent $\mathrm{LaCoO}_{3}$. Moreover, highly covalent oxides exhibit pH-dependent OER activities (on the RHE scale), whereas $\mathrm{LaCoO}_{3}$ shows the $\mathrm{pH}$-independent OER activity expected from the conventional OER mechanism. In light of these findings, we discuss potential OER mechanisms that are fundamentally different from the conventional scheme, which involve redox reactions of lattice oxygen and non-concerted proton-electron transfer steps to explain the lattice oxygen oxidation and the $\mathrm{pH}$-dependent OER activity observed with highly covalent and active catalysts.

\section{Results and discussion}

Evidence of lattice oxygen oxidation during OER. Here, we compare the participation of lattice oxygen oxidation in the OER among $\mathrm{LaCoO}_{3}, \quad \mathrm{La}_{0.5} \mathrm{Sr}_{0.5} \mathrm{CoO}_{3-\delta}, \mathrm{Pr}_{0.5} \mathrm{Ba}_{0.5} \mathrm{CoO}_{3-\delta}$ (that is, double perovskite $\mathrm{PrBaCo}_{2} \mathrm{O}_{5+\delta}$ ) and $\mathrm{SrCoO}_{3-\delta}$. It is of particular interest to examine the role of metal-oxygen covalency on the

\footnotetext{
'Department of Mechanical Engineering, Massachusetts Institute of Technology, Cambridge, Massachusetts 02139, USA. ${ }^{2}$ Leiden Institute of Chemistry, Leiden University, PO Box 9502, 2300 RA, Leiden, The Netherlands. ${ }^{3}$ Department of Materials Science and Engineering, Massachusetts Institute of Technology, Cambridge, Massachusetts 02139, USA. ${ }^{4}$ Research Laboratory of Electronics, Massachusetts Institute of Technology, Cambridge, Massachusetts 02139, USA. ${ }^{5}$ Dipartimento di Scienza dei Materiali, Università di Milano-Bicocca, Milano, Italy. †Present addresses: FRE 3677 'Chimie du Solide et Energie', Collège de France, 75231 Paris Cedex 05, France; Réseau sur le Stockage Electrochimique de I'Energie (RS2E), FR CNRS 3459, 80039

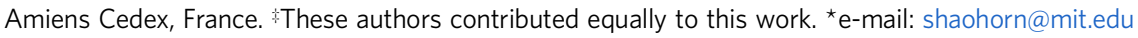



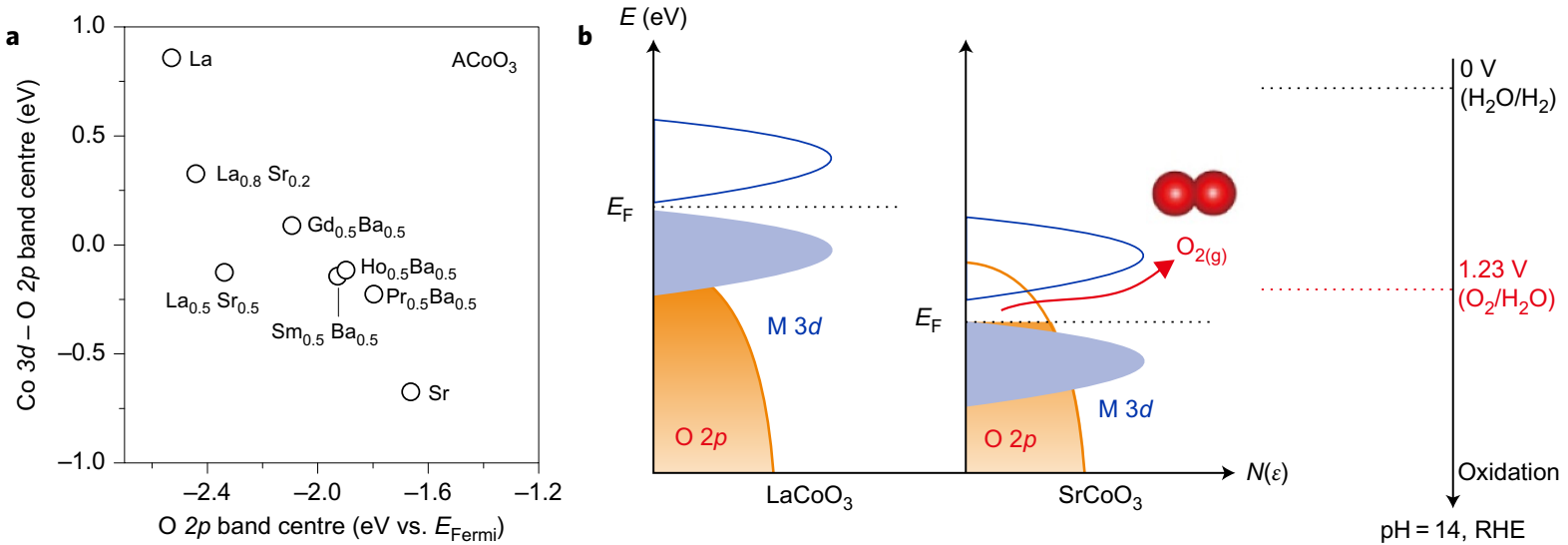

Figure 1 | Electronic structures of Co-containing perovskite oxides. a, Difference between the Co $3 d$-band centre and the $\mathrm{O} 2 p$-band centre versus the O $2 p$-band centre relative to the Fermi level for stoichiometric $\mathrm{ACoO}_{3}$ perovskites. Details of the computational approaches are provided in the Supplementary Information. $\mathbf{b}$, Schematic rigid band diagrams of $\mathrm{LaCoO}_{3}$ and $\mathrm{SrCoO}_{3}$. The position of the $\mathrm{O}_{2} / \mathrm{H}_{2} \mathrm{O}$ redox couple at pH $14\left(4 \mathrm{OH} \rightarrow \mathrm{O}_{2}+2 \mathrm{H}_{2} \mathrm{O}+4 \mathrm{e}^{-}\right)$is $1.23 \mathrm{~V}$ versus $\mathrm{RHE}$, as shown schematically on the right. The relationship between voltages under the RHE and standard hydrogen electrode (SHE) scale is $\varepsilon_{\mathrm{RHE}}=\varepsilon_{\mathrm{SHE}}+59 \mathrm{mV} \times \mathrm{pH}$.

participation of lattice oxygen oxidation in the OER. Density functional theory (DFT) studies ${ }^{19,20}$ have shown that substituting trivalent ions such as $\mathrm{La}^{3+}$ with divalent ions such as $\mathrm{Sr}^{2+}$ on the A-site of the perovskite structure $\left(\mathrm{ABO}_{3}\right)$ moves the Fermi level closer to the computed $\mathrm{O} 2 p$-band centre, which is accompanied by a reduced energy gap between the metal $3 d$ and $\mathrm{O} 2 p$-band centres (Fig. 1a), in agreement with work by Cheng and co-authors ${ }^{32}$. As the Fermi level moves down in energy and closer to the $\mathrm{O} 2 p$ states from $\mathrm{LaCoO}_{3}$ to $\mathrm{SrCoO}_{3}$, the antibonding states below the Fermi level exhibit greater oxygen character, indicative of greater covalency of the metal-oxygen bond ${ }^{33}$. Similar hybridization has been reported for layered metal chalcogenides ${ }^{34}$, perovskite-like cuprates ${ }^{35}$ and layered $\mathrm{Li}_{x} \mathrm{CoO}_{2}(x=\sim 0)^{36}$. The oxidation of lattice oxygen in the perovskites becomes thermodynamically favourable when $\mathrm{O} 2 p$ states at the perovskite Fermi level lie above the redox energy of the $\mathrm{O}_{2} / \mathrm{H}_{2} \mathrm{O}$ couple, as shown in Fig. 1b. Lattice oxygen oxidation is fundamentally different from oxygen intercalation (oxygen vacancy filling via $\left.\mathrm{ACoO}_{3-\delta}+2 \delta \mathrm{OH}^{-} \rightarrow \mathrm{ACoO}_{3}+\delta \mathrm{H}_{2} \mathrm{O}+2 \delta \mathrm{e}^{-}\right)$upon the oxidation of oxygen-deficient perovskites in an alkaline electrolyte ${ }^{37-39}$, which is driven by the energy difference between the $\mathrm{H}_{2} \mathrm{O} / \mathrm{H}_{2}$ redox couple and the Co $3 d$ states at the Fermi level of oxides (Fig. 1b).

OLEMS was used to detect the participation of lattice oxygen oxidation in the OER catalysed by these Co-based perovskites with different metal-oxygen covalency. $\mathrm{LaCoO}_{3}, \mathrm{La}_{0.5} \mathrm{Sr}_{0.5} \mathrm{CoO}_{3-\delta}$, $\mathrm{Pr}_{0.5} \mathrm{Ba}_{0.5} \mathrm{CoO}_{3-\delta}$ and $\mathrm{SrCoO}_{3-\delta}$ were prepared by conventional solid-state synthesis (see Methods). These oxides are stable in bulk during OER, in contrast to $\mathrm{Ba}_{0.5} \mathrm{Sr}_{0.5} \mathrm{Co}_{0.8} \mathrm{Fe}_{0.2} \mathrm{O}_{3-\delta}$, which becomes amorphous during $\mathrm{OER}^{40,41}$. In this work, we assert that oxides are not stable in bulk during OER, when considerable amorphization and loss of metal ions for oxide particles following OER are clearly discernable using transmission electron microscopy and associated spectroscopy, as reported previously ${ }^{40,41}$. This definition is different from the thermodynamic instability of oxides described in previous work ${ }^{42}$, which indicates that oxides are formally unstable when interfacing with aqueous electrolytes free of metal cations. Here, the oxide particles were dispersed on a gold disk electrode and labelled with ${ }^{18} \mathrm{O}$ by potentiostatic holding at 1.6 V versus $\mathrm{Au}$ in $\mathrm{H}_{2}{ }^{18} \mathrm{O}$-labelled 0.1 M KOH solution for $10 \mathrm{~min}$ (see Methods and Supplementary Fig. 19). After rinsing with ${ }^{16} \mathrm{O}$ water to remove $\mathrm{H}_{2}{ }^{18} \mathrm{O}$, OLEMS measurements were performed on these oxide electrodes in a $0.1 \mathrm{M} \mathrm{KOH}$ solution of $\mathrm{H}_{2}{ }^{16} \mathrm{O}$ using cyclic voltammetry $(\mathrm{CV})$. The OER activities of these oxides on
Au during OLEMS (Supplementary Fig. 1) were found to be similar to those measured by rotating disk electrode (RDE) measurements on glassy carbon (Supplementary Fig. 2), which are also consistent with those reported previously ${ }^{19,40,41}$. Oxygen gas of different molecular weights generated during OER was measured in situ by mass spectroscopy, where the signal for mass-to-charge ratio $m / z=32$ represents ${ }^{32} \mathrm{O}_{2}\left({ }^{16} \mathrm{O}^{16} \mathrm{O}\right), m / z=34$ represents ${ }^{34} \mathrm{O}_{2}\left({ }^{16} \mathrm{O}^{18} \mathrm{O}\right)$ and $m / z=36$ represents ${ }^{36} \mathrm{O}_{2}\left({ }^{18} \mathrm{O}^{18} \mathrm{O}\right)$. The signal of $m / z=34$ was normalized by the signal of $m / z=32$ to account for natural isotopic abundance $(\sim 0.2 \%)$. This normalized signal of $m / z=34$ to $m / z=32$ and the mass signal of $m / z=36$ collected from the OER in the first cycle are shown in Fig. 2a and b, respectively. As the signals of $m / z=32$ detected by OLEMS include both molecular oxygen formed during the OER and oxygen from ambient air, the ratio of OER current involving $\mathrm{m} / z=34$ and $\mathrm{m} / \mathrm{z}=36$ to that with $m / z=32$ could not be quantified in this study.

Neither normalized $m / z=34$ (Fig. 2a) nor $m / z=36$ (Fig. 2b) was detected during the OER for $\mathrm{LaCoO}_{3}$, indicating there was no oxygen from the $\mathrm{LaCoO}_{3}$ lattice in the molecular oxygen evolved. For $\mathrm{La}_{0.5} \mathrm{Sr}_{0.5} \mathrm{CoO}_{3-\delta}$ and $\mathrm{Pr}_{0.5} \mathrm{Ba}_{0.5} \mathrm{CoO}_{3-\delta}$, the normalized $\mathrm{m} / z=34$ rose slightly above the natural abundance of ${ }^{18} \mathrm{O}$ (Fig. 2a), and small signals of $m / z=36$ were detected at $1.6 \mathrm{~V}$ versus RHE and above (Fig. 2b), indicating successful ${ }^{18} \mathrm{O}$ labelling and the involvement of lattice oxygen in the OER. Of significance, lattice oxygen oxidation during the OER measured from $\mathrm{SrCoO}_{3-\delta}$ was more pronounced than that for $\mathrm{La}_{0.5} \mathrm{Sr}_{0.5} \mathrm{CoO}_{3-\delta}$, as both the normalized $m / z=34$ and $m / z=36$ signals detected from $\mathrm{SrCoO}_{3-\delta}$ were greater, with lower onset voltages (1.5 V versus RHE and greater), as shown in Fig. 2. The detection of ${ }^{16} \mathrm{O}^{18} \mathrm{O}$ during the OER (one oxygen from the electrolyte and the other from the oxide lattice) as well as ${ }^{18} \mathrm{O}^{18} \mathrm{O}$ (two oxygens from the oxide lattice) requires the oxidation of lattice oxygen from metal oxides and the formation of oxygen vacancies during the OER. The release of ${ }^{16} \mathrm{O}^{16} \mathrm{O},{ }^{16} \mathrm{O}^{18} \mathrm{O}$ and ${ }^{18} \mathrm{O}^{18} \mathrm{O}$ for $\mathrm{La}_{0.5} \mathrm{Sr}_{0.5} \mathrm{CoO}_{3-\delta}, \quad \mathrm{Pr}_{0.5} \mathrm{Ba}_{0.5} \mathrm{CoO}_{3-\delta}$ and $\mathrm{SrCoO}_{3-\delta}$, which are stable in bulk during OER, differs from those for catalysts that are amorphized in bulk under OER, such as $\mathrm{Ba}_{0.5} \mathrm{Sr}_{0.5} \mathrm{Co}_{0.8} \mathrm{Fe}_{0.2} \mathrm{O}_{3-\delta}$ (refs 40,41), where ${ }^{16} \mathrm{O}^{16} \mathrm{O}$ and ${ }^{18} \mathrm{O}^{18} \mathrm{O}$ are released independently of the potential in the negative sweep (Supplementary Figs 1 and 3). The amount of ${ }^{18} \mathrm{O}$ detected during the OER was used to estimate the number of monolayers, or thickness normal to the (001) surface, in the cubic perovskite structure involved in the OER for $\mathrm{LaCoO}_{3}, \mathrm{La}_{0.5} \mathrm{Sr}_{0.5} \mathrm{CoO}_{3-\delta}, \mathrm{Pr}_{0.5} \mathrm{Ba}_{0.5} \mathrm{CoO}_{3-\delta}$ and $\mathrm{SrCoO}_{3-\delta}$ (Supplementary Table 3 and Supplementary Fig. 4). The minimum oxide thickness involved during OER was estimated to 

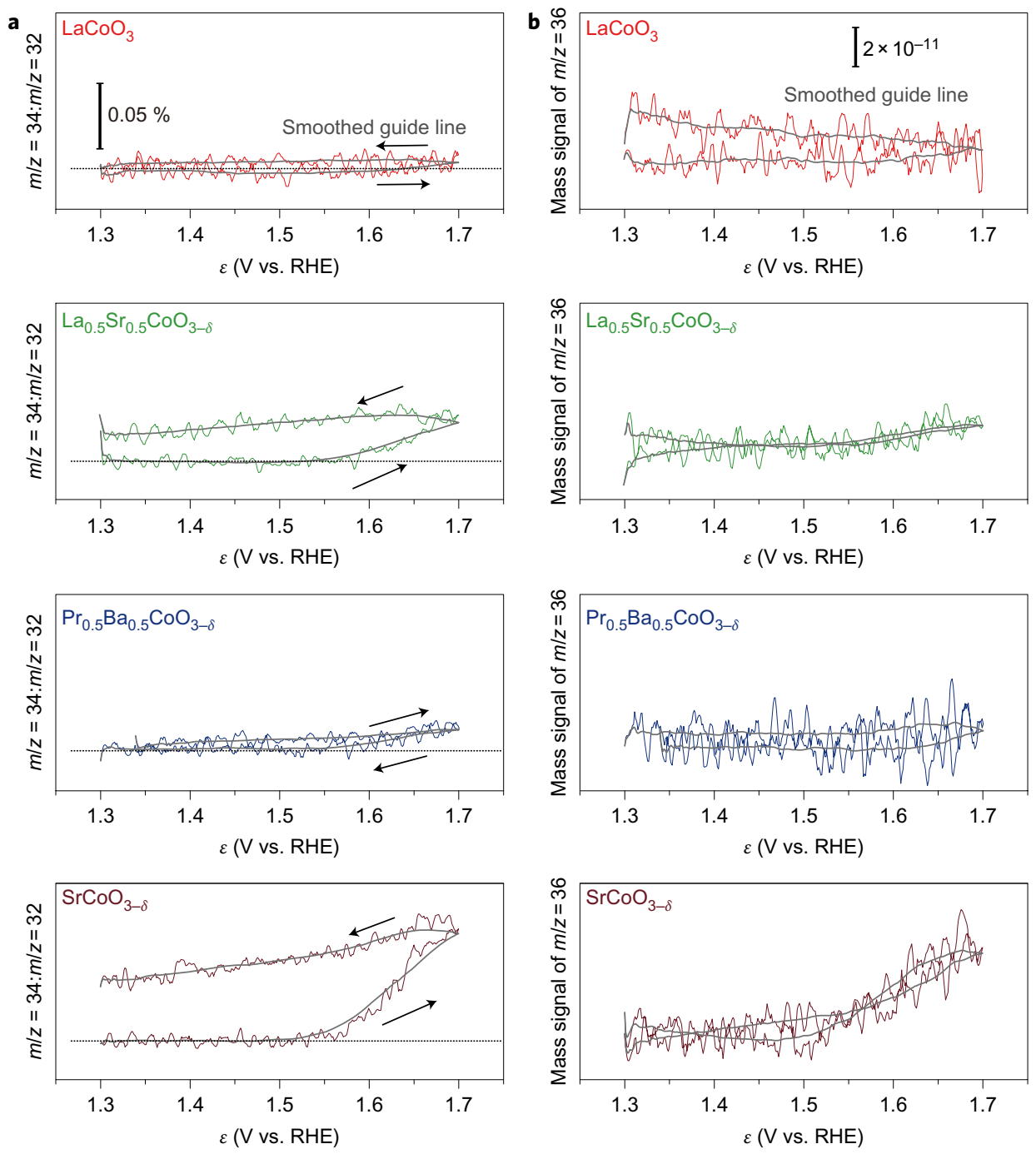

Figure 2 | Direct evidence of lattice oxygen oxidation involved in the OER of ${ }^{18} \mathrm{O}$-labelled perovskites. Data were measured in $0.1 \mathrm{M} \mathrm{KOH}$ by OLEMS at a scan rate of $2 \mathrm{mV} \mathrm{s}^{-1}$ (no gas bubbling). $\mathbf{a}_{1}{ }^{34} \mathrm{O}_{2} /{ }^{32} \mathrm{O}_{2}$ ratios, where the straight lines correspond to the natural abundance of ${ }^{18} \mathrm{O}$ of $0.2 \%$. The arrows indicate forward and backward scans. $\mathbf{b},{ }^{36} \mathrm{O}_{2}$ signal. All data were taken from the first cycle (data from the second cycle are provided in Supplementary Fig. 1). ${ }^{34} \mathrm{O}_{2}$ but not ${ }^{36} \mathrm{O}_{2}$ was detected in the cathodic sweep at potentials where there is no OER activity. The origin of this is not understood. We speculate that chemical processes triggered by OER with lattice oxygen participation might be responsible for the evolution of ${ }^{34} \mathrm{O}_{2}$ in the cathodic sweep, but further studies are needed.

be $\sim 0.5 \mathrm{~nm}$ for $\mathrm{LaCoO}_{3}$, indicating a surface OER process. In contrast, the minimum thicknesses estimated for $\mathrm{La}_{0.5} \mathrm{Sr}_{0.5} \mathrm{CoO}_{3-\delta}$, $\mathrm{Pr}_{0.5} \mathrm{Ba}_{0.5} \mathrm{CoO}_{3-\delta}$ and $\mathrm{SrCoO}_{3-\delta}$ were $\sim 0.7,1.5$ and $14 \mathrm{~nm}$, respectively, demonstrating the participation of oxygen from the oxides in the OER. Having considerable oxygen originating from oxides participating in the OER is not surprising, considering that the bulk diffusion of oxygen ions at room temperature can be large (for example, $\tilde{D}_{O} \approx 10^{-11} \mathrm{~cm}^{2} \mathrm{~s}^{-1}$ for $\left.\mathrm{SrCoO}_{3-\delta}\right)^{38}$. The physical origin of the oxidation of lattice oxygen can be attributed to a shift of the Fermi level deeper into the $\mathrm{O} 2 p$ band. When the $\mathrm{O}_{2} / \mathrm{H}_{2} \mathrm{O}$ redox potential aligns with the energy corresponding to the $\mathrm{O} 2 p$ states of the oxide, holes are created in the oxygen band, which can allow oxidized oxygen ions to form $\left(\mathrm{O}_{2}\right)^{n-}$ species, analogous to anionic redox of chalcogenides ${ }^{34}$ and/or molecular oxygen $^{33}$ (leaving oxygen vacancies behind). The more $\mathrm{O}_{2}$ generated during OER, the greater the value for ${ }^{18} \mathrm{O} /{ }^{16} \mathrm{O}$ (Supplementary Fig. 5), indicating that the amount of lattice oxygen detected during the OER process depends on the position of the $\mathrm{O} 2 p$ states relative to the Fermi level and correlates with the OER activity for this family of oxides.
The participation of lattice oxygen oxidation in the OER for $\mathrm{La}_{0.5} \mathrm{Sr}_{0.5} \mathrm{CoO}_{3-\delta}, \mathrm{Pr}_{0.5} \mathrm{Ba}_{0.5} \mathrm{CoO}_{3-\delta}$ and $\mathrm{SrCoO}_{3-\delta}$ highlights a fundamental mechanistic shift from the conventional OER mechanism involving four concerted proton-electron-transfer steps on surface metal ions ${ }^{11,12}$. The lattice oxygen oxidation found in the OER in this study is distinct from the participation of active vacancy sites in the $\mathrm{OER}^{43}$ or the oxygen intercalation reaction in oxygendeficient oxides ${ }^{37-39}$, which largely involve the redox of the cation and do not form $\mathrm{O}-\mathrm{O}$ bonds involving metal oxide lattice oxygen. As previous work shows that $\mathrm{La}_{0.8} \mathrm{Sr}_{0.2} \mathrm{CoO}_{3-\delta}$ and $\mathrm{La}_{0.6} \mathrm{Sr}_{0.4} \mathrm{CoO}_{3-\delta}$ exhibit pH-dependent OER activity on the RHE scale ${ }^{16,17}$, we investigate in the following whether the participation of lattice oxygen oxidation in the OER is associated with non-concerted proton-electron transfer processes ${ }^{14}$, giving rise to $\mathrm{pH}$-dependent OER activity.

pH-dependent OER kinetics. Oxides that exhibited the oxidation of lattice oxygen during the OER (that is, $\mathrm{La}_{0.5} \mathrm{Sr}_{0.5} \mathrm{CoO}_{3-\delta}$, $\mathrm{Pr}_{0.5} \mathrm{Ba}_{0.5} \mathrm{CoO}_{3-\delta}$ and $\mathrm{SrCoO}_{3-\delta}$; Fig. 2) were found to have $\mathrm{pH}$-dependent OER kinetics on the RHE scale (Fig. 3 and 

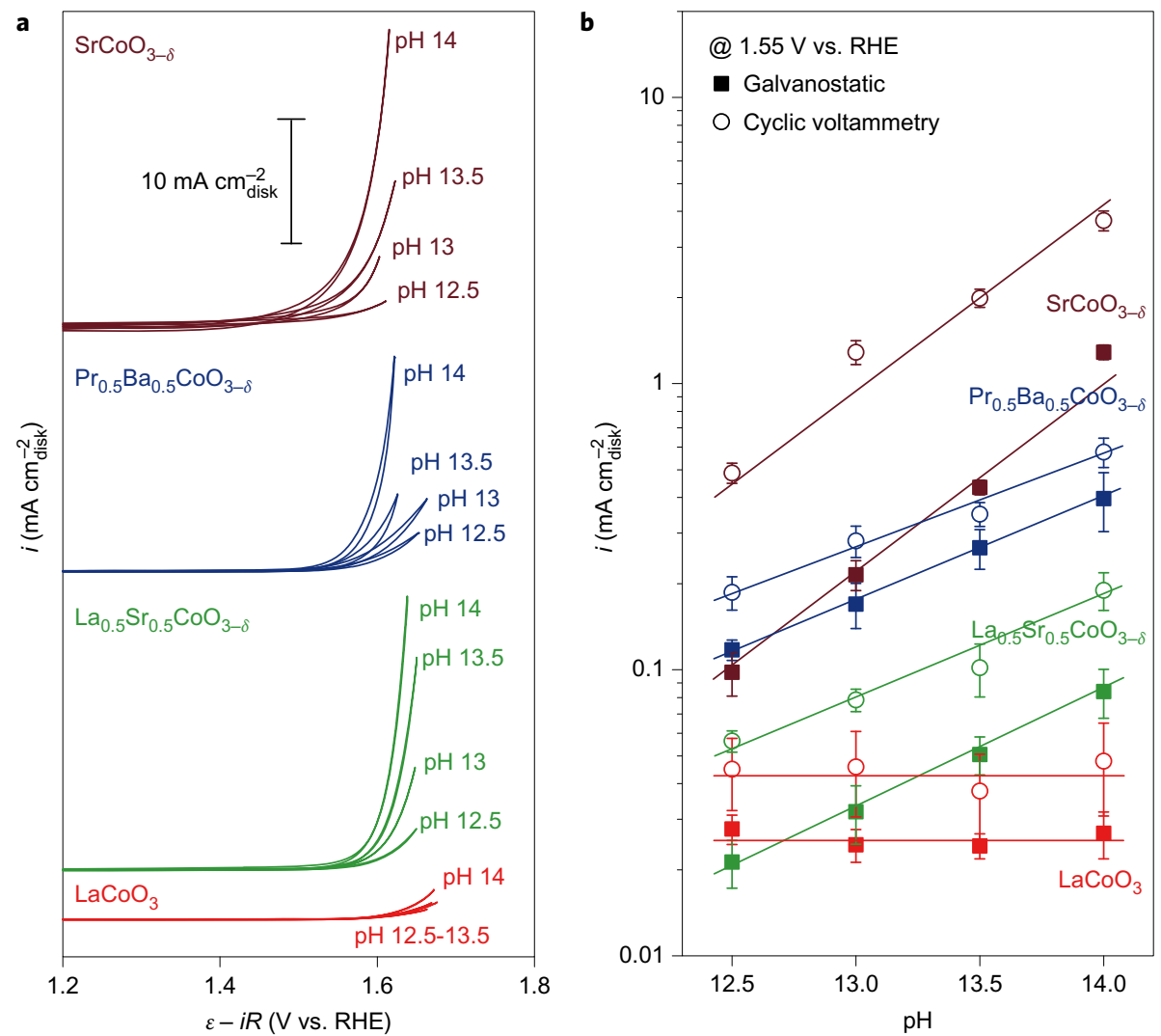

Figure 3 I pH-dependent OER activity on the RHE scale. a, $\mathrm{CV}$ measurements from $\mathrm{O}_{2}$-saturated $0.03 \mathrm{M} \mathrm{KOH}(\mathrm{pH} 12.5)$ to $1 \mathrm{M} \mathrm{KOH}(\mathrm{pH} 14)$ recorded at $10 \mathrm{mV} \mathrm{s}^{-1}$. b. Specific OER activity (current normalized by oxide BET surface area) at $1.55 \mathrm{~V}$ versus RHE after iR correction as a function of pH. The nominal oxide loading is $0.25 \mathrm{mg}_{\text {oxide }} \mathrm{cm}_{\text {disk. }}^{-2}$ Error bars represent standard deviation of three measurement results.

Supplementary Figs 6,7,8), while $\mathrm{LaCoO}_{3}$ without any lattice oxygen oxidation exhibited $\mathrm{pH}$-independent OER kinetics. RHE was used as the reference electrode to ensure that the OER overpotential with respect to the equilibrium $\mathrm{O}_{2} / \mathrm{H}_{2} \mathrm{O}$ redox potential remained identical across different values of $\mathrm{pH}$ (ref. 17). The $\mathrm{pH}$ dependence of OER activity on the RHE scale indicates the presence of non-concerted proton-electron transfer steps during the OER, where the rate-limiting step is either a proton transfer step or preceded by acid/base equilibrium ${ }^{14,17}$. OER currents from $\mathrm{CV}$ measurements were found to increase with increasing $\mathrm{pH}$ for $\mathrm{La}_{0.5} \mathrm{Sr}_{0.5} \mathrm{CoO}_{3-\delta}, \mathrm{Pr}_{0.5} \mathrm{Ba}_{0.5} \mathrm{CoO}_{3-\delta}$ and $\mathrm{SrCoO}_{3-\delta}$, but remained unchanged for $\mathrm{LaCoO}_{3}$, as shown in Fig. 3a. The intrinsic OER activities of $\mathrm{LaCoO}_{3}, \mathrm{La}_{0.5} \mathrm{Sr}_{0.5} \mathrm{CoO}_{3-\delta}, \mathrm{Pr}_{0.5} \mathrm{Ba}_{0.5} \mathrm{CoO}_{3-\delta}$ and $\mathrm{SrCoO}_{3-\delta}$, as estimated by either the surface-area-normalized current at $1.55 \mathrm{~V}$ versus RHE (Fig. 3b) or the OER potential at $0.2 \mathrm{~mA} \mathrm{~cm}$ oxide (Supplementary Fig. 6) from CV and galvanostatic measurements, are compared as a function of $\mathrm{pH}$. The specific OER activities of these oxides, with error bars, are presented in Supplementary Figs 7 and 8. Greater metal-oxygen covalency (Fig. 1) and lattice oxygen oxidation (Fig. 2) correlates with increasing OER activity, which is most evident at $\mathrm{pH} 14$ (Fig. 3b). Significantly, $\mathrm{SrCoO}_{3-\delta}$ was found to have OER activity approximately three times greater than that of $\operatorname{Pr}_{0.5} \mathrm{Ba}_{0.5} \mathrm{CoO}_{3-\delta}$ (ref. 19), one of the most active and stable oxides previously reported for the OER.

Both CV and galvanostatic measurements show that the intrinsic OER activity of $\mathrm{LaCoO}_{3}$ is independent of $\mathrm{pH}$, while those for $\mathrm{La}_{0.5} \mathrm{Sr}_{0.5} \mathrm{CoO}_{3-\delta}, \operatorname{Pr}_{0.5} \mathrm{Ba}_{0.5} \mathrm{CoO}_{3-\delta}$ and $\mathrm{SrCoO}_{3-\delta}$ are $\mathrm{pH}-$ dependent (increasing the $\mathrm{pH}$ from 12.5 to 14 led to greater intrinsic OER activities by one order of magnitude). Interestingly, the specific OER currents measured from CV can be consistently higher than those from galvanostatic measurements. This difference can be attributed to the contribution from oxygen intercalation following the oxidation of $\mathrm{Co}^{3+}$ ions (as evidenced by the redox peak at $\sim 1.2 \mathrm{~V}$ versus RHE in Supplementary Fig. 9) in oxygen-deficient perovskites ${ }^{37-39}$ to the OER current measured from CV (measured over minutes), which is negligible in galvanostatic measurements (with much lower rates, measured over hours). This argument is further supported by the fact that the difference in the OER activity between $\mathrm{CV}$ and galvanostatic measurements increases with increasing charge associated with oxygen vacancy filling of the oxides before OER (Fig. 3 and Supplementary Fig. 10). Therefore, galvanostatic measurements provide a more accurate measure of OER activity than CV.

OER mechanisms with lattice oxygen oxidation. The conventional OER mechanism ${ }^{11,12}$ on surface metal sites (Fig. 4a and Supplementary Fig. 11) catalyses OER on the oxide surface, which cannot evolve more than $\sim 0.4 \mathrm{~nm}$ of ${ }^{18} \mathrm{O}$ during OER after ${ }^{18} \mathrm{O}$-labelling. The observed ${ }^{18} \mathrm{O}$ released in the OER for $\mathrm{La}_{0.5} \mathrm{Sr}_{0.5} \mathrm{CoO}_{3-\delta}, \mathrm{Pr}_{0.5} \mathrm{Ba}_{0.5} \mathrm{CoO}_{3-\delta}$ and $\mathrm{SrCoO}_{3-\delta}$ can be attributed to oxide lattice participation greater than $\sim 0.4 \mathrm{~nm}$, which cannot be explained by the traditional OER mechanism. In addition, this traditional mechanism with concerted proton-electron transfer cannot explain the pH-dependent OER activity on the above oxides. Therefore, mechanisms that are fundamentally different from the conventional scheme $\mathrm{e}^{11,12}$ are needed to explain the involvement of lattice oxygen oxidation $\left({ }^{34} \mathrm{O}_{2}\right.$ and/or ${ }^{36} \mathrm{O}_{2}$ detected) in the OER for $\mathrm{La}_{0.5} \mathrm{Sr}_{0.5} \mathrm{CoO}_{3-\delta}, \mathrm{Pr}_{0.5} \mathrm{Ba}_{0.5} \mathrm{CoO}_{3-\delta}$, and $\mathrm{SrCoO}_{3-\delta}$, as well as their $\mathrm{pH}$-dependent OER kinetics. Conversely, given the absence of lattice oxygen oxidation and $\mathrm{pH}$-independent OER kinetics observed for $\mathrm{LaCoO}_{3}$, the OER kinetics on $\mathrm{LaCoO}_{3}$ can be explained by the conventional concerted proton-electron transfer mechanism on surface cobalt sites (Fig. $4 a)^{11,12}$. Considering the 

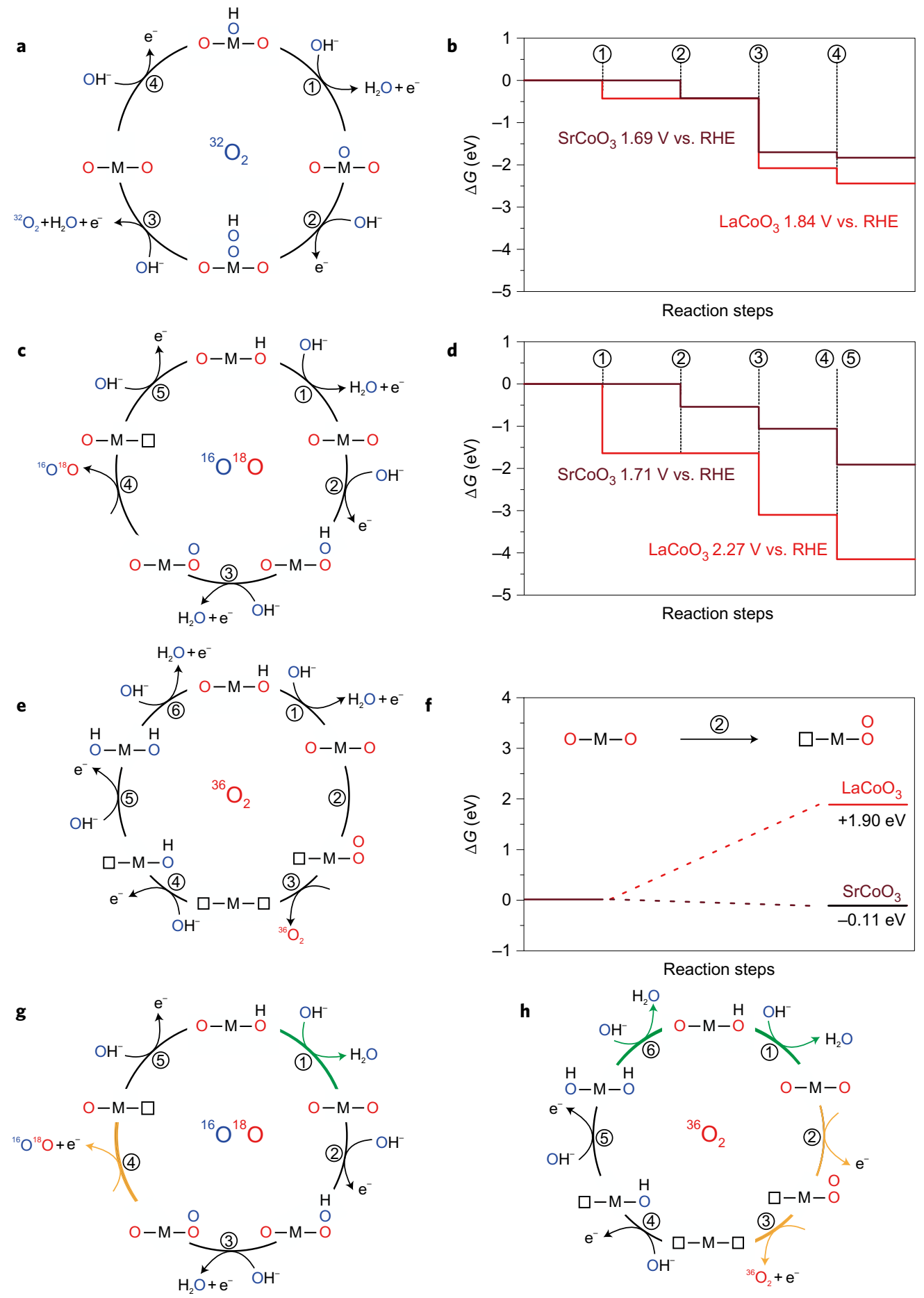

Figure 4 | OER mechanisms with concerted and non-concerted proton-electron transfer. a, Conventional OER mechanism involving concerted protonelectron transfers on surface metal sites ${ }^{12,58,59}$, with oxygen from the electrolyte in blue and from the oxide lattice in red. c,e, Possible OER mechanisms involving concerted proton-electron transfer on surface oxygen sites to yield ${ }^{16} \mathrm{O}^{18} \mathrm{O}\left({ }^{34} \mathrm{O}_{2}\right)$ and ${ }^{18} \mathrm{O}^{18} \mathrm{O}\left({ }^{36} \mathrm{O}_{2}\right)$, respectively. b,d, Computed free energies $(\Delta G)$ of coupled proton-electron transfer OER steps on the metal (b) and oxygen (d) sites of the $(001) \mathrm{MO}_{2}$ surface to form ${ }^{32} \mathrm{O}_{2}$, respectively, where all the steps are thermodynamically downhill. f, The computed $\Delta G$ of (001) $\mathrm{MO}_{2}$ shows that the formation of the O-O bond is energetically favourable for surface oxygen sites of $\mathrm{SrCoO}_{3}$ but not for $\mathrm{LaCoO}_{3} \cdot \mathbf{g}$,h, Possible non-concerted proton-electron transfer OER mechanisms that evolve ${ }^{34} \mathrm{O}_{2}$ ( $\mathbf{g}$ ) and ${ }^{36} \mathrm{O}_{2}$ (h) with $\mathrm{pH}$-dependent OER activity, with electron-transfer steps in yellow, proton-transfer steps in green and charged intermediates accommodated by metal ion valence changes.

cobalt sites of the (001) $\mathrm{CoO}_{2}$ surface, the computed free energies of concerted proton-electron transfer steps show that the $\mathrm{O}-\mathrm{O}$ bond formation (step 2 in Fig. 4a) is rate-limiting for $\mathrm{LaCoO}_{3}$, in agreement with previous works ${ }^{11,44}$. Increasing metal-oxygen covalency from $\mathrm{LaCoO}_{3}$ to $\mathrm{SrCoO}_{3}$ was found to promote OER kinetics on the metal sites in this concerted mechanism (Fig. 4b), as indicated by the lowered potential needed for all steps becoming thermodynamically downhill.

We next discuss reaction schemes involving the oxidation of lattice oxygen and concerted proton-electron transfers to explain 


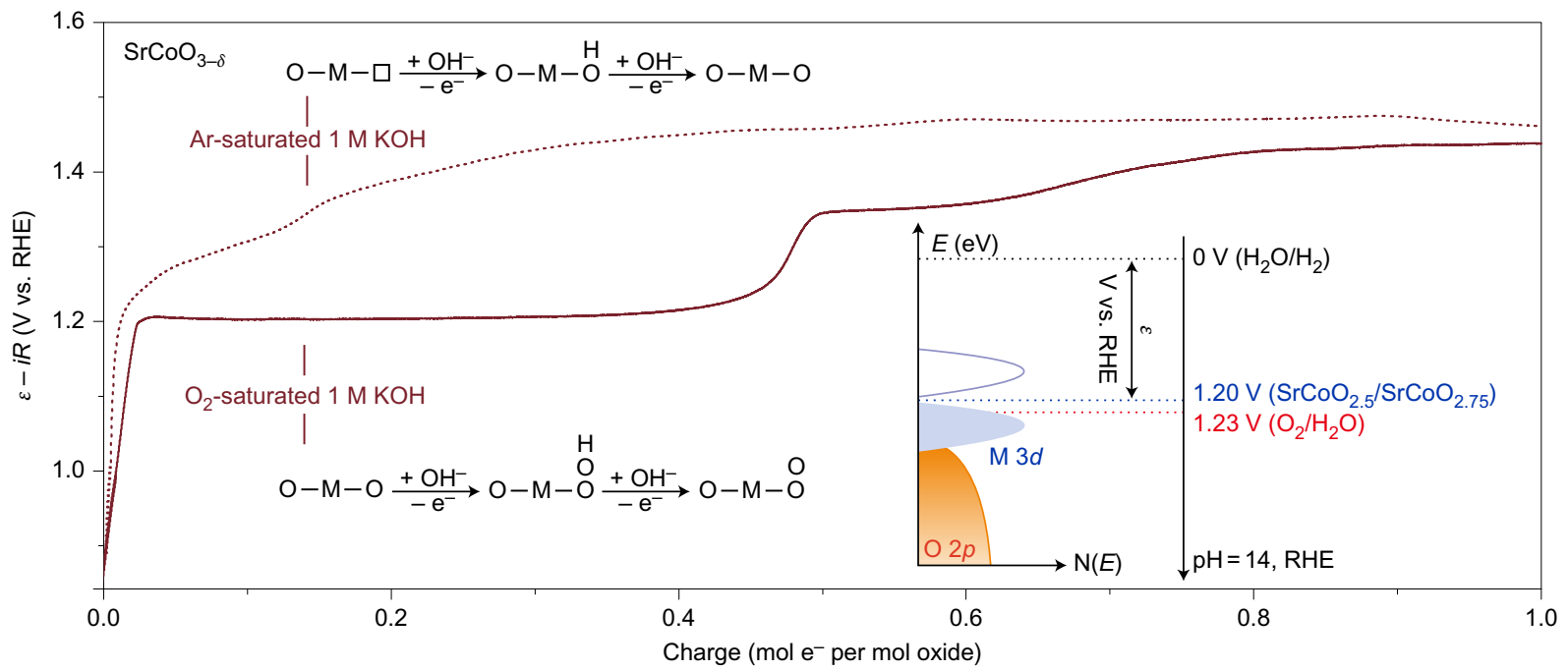

Figure 5 | Electrochemical oxygen intercalation into brownmillerite $\mathrm{SrCoO}_{3-\delta}$ followed by the $\mathrm{OER}_{\text {. Galvanostatic charging (iR-corrected) of } \mathrm{SrCoO}}-\delta$ in $\mathrm{O}_{2}$-saturated (solid line) and Ar-saturated (dotted line) $1 \mathrm{M} \mathrm{KOH}$ as a function of charge passed at $7 \mathrm{~mA} \mathrm{goxide}^{-1}$. The oxide loading was $0.25 \mathrm{mg}_{\text {oxide }} \mathrm{cm}_{\text {disk }}^{-2}$ mixed with a carbon loading of $0.05 \mathrm{mg}_{\text {carbon }} \mathrm{cm}_{\text {disk. }}^{-2}$. Inset scheme: relationship between the measured voltage of oxygen intercalation at $\mathrm{pH} 14$ (unit activity for $\mathrm{OH}^{-}$) and oxide band structure.

the detection of ${ }^{34} \mathrm{O}_{2}$ and ${ }^{36} \mathrm{O}_{2}$, which will be further modified to include decoupled proton-electron transfers to explain the observed pH-dependent OER activities. The formation of ${ }^{34} \mathrm{O}_{2}$ can be explained by charge transfer steps on surface oxygen sites. One likely mechanism is shown in Fig. 4c, though other possibilities may exist. The first three steps on surface oxygen sites are concerted proton-electron transfers analogous to those on metal sites in Fig. 4a; these are followed by a chemical step to produce molecular ${ }^{34} \mathrm{O}_{2}\left({ }^{16} \mathrm{O}^{18} \mathrm{O}\right)$ and an oxygen vacancy, and a subsequent concerted proton-electron transfer step to regenerate the $\mathrm{O}-\mathrm{M}-\mathrm{OH}$ surface. Increasing metal-oxygen covalency from $\mathrm{LaCoO}_{3}$ to $\mathrm{SrCoO}_{3}$ promotes OER activity for the surface oxygen sites, as is evident from the lower computed potential necessary for all reaction steps to become thermodynamically favourable (Fig. 4d). The computed thermodynamic OER potential on surface oxygen sites of $\mathrm{SrCoO}_{3}$ is comparable to that on surface Co sites (Fig. 4b), suggesting that both can be active for OER. In contrast, surface Co sites (Fig. 4b) of $\mathrm{LaCoO}_{3}$ are more active than surface oxygen sites, suggesting that surface Co sites govern the OER activity. Note that the ratelimiting step of OER on $\mathrm{LaCoO}_{3}$ was found to be different from that for $\mathrm{SrCoO}_{3}$, where $\mathrm{O}-\mathrm{O}$ bond formation on surface metal and oxygen sites (step 2 in Fig. $4 \mathrm{a}, \mathrm{c}$ ) and $\mathrm{OH}^{-}$adsorption onto surface metal and oxygen sites (step 1 in Fig. 4a,c) limits the OER kinetics of $\mathrm{LaCoO}_{3}$ and $\mathrm{SrCoO}_{3}$, respectively (Fig. 4d). Increasing Co-O covalency from $\mathrm{LaCoO}_{3}$ to $\mathrm{SrCoO}_{3}$ is associated with moving the oxide Fermi level below the $\mathrm{O}_{2} / \mathrm{H}_{2} \mathrm{O}$ redox energy (Fig. 1b); the oxide surface becomes more negatively charged when equilibrated with the electrolyte and preferentially acts as a Brønsted base, making deprotonation by $\mathrm{OH}^{-}$more difficult for $\mathrm{Sr}$-substituted $\mathrm{LaCoO}_{3}$ (ref. 45).

The formation of ${ }^{36} \mathrm{O}_{2}$, most pronounced for $\mathrm{SrCoO}_{3-\delta}$, requires the formation of an ${ }^{18} \mathrm{O}-{ }^{18} \mathrm{O}$ bond from two surface oxygen ions of the oxide. Although other possibilities may exist (Supplementary Fig. 12), a likely mechanism is shown in Fig. 4e. The mechanism consists of two chemical steps, which create an $\mathrm{O}-\mathrm{O}$ bond, then a molecular oxygen from lattice oxygen sites via the formation of two oxygen vacancies (steps 2 and 3 in Fig. 4e). The remaining steps of the mechanism involve four concerted proton-electron transfers-two for regenerating the surface oxygen sites and two associated with deprotonating surface oxygen ions. DFT calculations show that the chemical step to form an $\mathrm{O}-\mathrm{O}$ bond and an oxygen vacancy from surface oxygen ions of $\mathrm{SrCoO}_{3}$ is thermodynamically favourable (Fig. 4 f and Supplementary Fig. 13). On the other hand, the $\mathrm{O}-\mathrm{O}$ bond formation from two surface oxygen ions of $\mathrm{LaCoO}_{3}$ is energetically unfavourable (Fig. 4f), which is consistent with previous findings that the energy penalty associated with oxygen vacancy formation increases with moving the Fermi level away from the $\mathrm{O} 2 p$-band centre ${ }^{20}$ (Supplementary Fig. 14) and the absence of lattice oxygen oxidation on $\mathrm{LaCoO}_{3}$.

The $\mathrm{pH}$-dependent OER activities on the RHE scale observed for $\mathrm{La}_{0.5} \mathrm{Sr}_{0.5} \mathrm{CoO}_{3-\delta}, \quad \mathrm{Pr}_{0.5} \mathrm{Ba}_{0.5} \mathrm{CoO}_{3-\delta}$ and $\mathrm{SrCoO}_{3-\delta}$ require the decoupling of some proton transfers from electron transfers in the reaction schemes in Fig. 4c,e. Two likely reaction schemes are proposed in Fig. 4g,h. It is postulated here that the rate-limiting step in the concerted mechanism (Fig. 4c,e)-deprotonation of hydroxyl groups $\mathrm{O}-\mathrm{M}^{n+}-\mathrm{OH}+\mathrm{OH}^{-} \rightarrow \mathrm{O}-\mathrm{M}^{(n-1)+}-\mathrm{O}+\mathrm{H}_{2} \mathrm{O}$ (highlighted in green)-has become non-concerted and decoupled from subsequent electron transfer during the evolution of molecular oxygen, $\mathrm{O}-\mathrm{M}^{(n-1)+}-\mathrm{OO} \rightarrow \mathrm{O}-\mathrm{M}^{n+}-\square+\mathrm{O}_{2}+\mathrm{e}^{-}$(highlighted in yellow). Nevertheless, we emphasize that decoupling of proton and electron transfers can also occur in other reaction steps in these OER mechanisms, and, ultimately, the $\mathrm{p} K_{\mathrm{a}}$ of such surface deprotonation determines the step that is responsible for the overall $\mathrm{pH}$-dependent kinetics ${ }^{14,46}$.

The proposed rate-limiting step for the OER kinetics of oxides with strong covalency, that is, the deprotonation of surface hydroxyl groups, is supported by the remarkably different kinetics of galvanostatic oxidation of brownmillerite $\mathrm{SrCoO}_{3-\delta}\left(\mathrm{SrCoO}_{3-\delta}+2 \delta \mathrm{OH}^{-} \rightarrow\right.$ $\mathrm{SrCoO}_{3}+\delta \mathrm{H}_{2} \mathrm{O}+2 \delta \mathrm{e}^{-}$) in Ar-saturated and $\mathrm{O}_{2}$-saturated $1 \mathrm{M}$ $\mathrm{KOH}$, as shown in Fig. 5. Galvanostatic oxidation of brownmillerite $\mathrm{SrCoO}_{3-\delta}$ in $\mathrm{O}_{2}$-saturated $1 \mathrm{M} \mathrm{KOH}$ led to the well-known plateau ${ }^{47}$ of oxygen intercalation, whereas oxidation with Ar saturation exhibited no clear plateau of oxygen intercalation. Oxygen vacancy filling into $\mathrm{SrCoO}_{3-\delta}$ is driven by the energy difference between the $\mathrm{H}_{2} \mathrm{O}$ / $\mathrm{H}_{2}$ redox couple and the Co $3 d$ states at the Fermi level of oxides (Fig. 5, inset), which should not be influenced by $\mathrm{Ar}$ or $\mathrm{O}_{2}$ saturation in the electrolyte. The kinetics of the oxygen filling of $\mathrm{SrCoO}_{3-\delta}$ oxygen vacancies in Ar-saturated electrolyte can be attributed to the slow deprotonation kinetics of surface hydroxyl groups, which is needed to intercalate oxygen ions into the oxide lattice. As our DFT calculations show that filling vacancies with $\mathrm{O}^{*}$ is more favourable than filling with $\mathrm{OH}^{*}$ on the Co-terminated (001) surface of brownmillerite $\left(-0.82 \mathrm{eV}\right.$ per $\mathrm{O}^{*}$ and $-0.40 \mathrm{eV}$ per $\mathrm{OH}^{\star}$ ) at $1.23 \mathrm{~V}$ versus RHE (Supplementary Fig. 15), surface oxygen vacancies in the $\mathrm{O}_{2}$-saturated electrolyte are filled 
preferentially by $\mathrm{O}_{2}$ rather than by $\mathrm{OH}^{-}$. The filling of surface vacancies with $\mathrm{O}^{*}$ rather than $\mathrm{OH}^{*}$ allows the oxygen intercalation to proceed through an $\mathrm{O}-\mathrm{M}-\mathrm{OOH}$ intermediate rather than $\mathrm{O}-\mathrm{M}-$ $\mathrm{OH}$ (step 3 instead of step 1 in Fig. 4b,d), rendering the faster kinetics observed in the $\mathrm{O}_{2}$-saturated electrolyte. Further support for the deprotonation being decoupled from electron transfer comes from the observation that the oxygen intercalation kinetics become more sluggish in the $\mathrm{O}_{2}$-saturated electrolyte when decreasing the $\mathrm{pH}$ from 14 to 13 (Supplementary Fig. 16).

The proposed OER mechanisms in Fig. 4g,h used to explain lattice oxygen oxidation and the $\mathrm{pH}$-dependent OER kinetics of highly covalent oxides bridge between the conventional OER mechanism ${ }^{11,12,14,15}$ of metal oxides and those reported for electrodeposited oxide films ${ }^{17,28,48}$. Oxygen exchange is shown to participate in the OER of $\mathrm{Co}-\mathrm{Pi}$ films electrodeposited in $\mathrm{Co}^{2+}$-phosphate-containing electrolytes under neutral conditions via ${ }^{18} \mathrm{O}$-isotopic labelling ${ }^{28,48}$, while no $\mathrm{pH}$-dependence of OER kinetics on the RHE scale is noted ${ }^{17,28}$, where proton-acceptor phosphate species governs the kinetics of surface deprotonation ${ }^{28}$ to enable high OER activity. Recent mechanistic studies of these catalysts move beyond charge transfer steps on metal sites and propose the involvement of oxygen redox chemistry mediated by oxygen holes (that is, $\mathrm{Co}^{4+}$ described as $\mathrm{Co}^{3+}$ and a hole in the $\mathrm{O}$ states ${ }^{30}$ promotes $\mathrm{O}-\mathrm{O}$ bond formation) in OER kinetics, similar to the mechanisms proposed here $\mathrm{e}^{28,30,48}$. Further support for the synergy in the OER mechanisms comes from the $\mathrm{pH}$-dependent OER kinetics on the RHE scale in basic solution reported for electrodeposited $(\mathrm{Ni}, \mathrm{Fe})$ $\mathrm{OOH}$ film ${ }^{18}$, which has been attributed to deprotonation leading to the formation of a negatively charged oxygenated intermediate ('active oxygen') participating in the OER, as suggested by surface-enhanced Raman spectroscopy ${ }^{18}$. Further studies are required to understand the role of non-concerted proton-electron transfer steps on the OER kinetics of electrodeposited oxide films and highly covalent oxides and the nature of surface oxygen participating in $\mathrm{O}-\mathrm{O}$ bond formation (for example, terminal oxygen, as proposed for electrodeposited films ${ }^{28,30,48}$, versus bridging oxygen, for covalent oxides in this study).

In summary, by combining electrochemical characterization with DFT studies, we have demonstrated that the bulk electronic structure of transition-metal oxides, namely the metal-oxygen covalency, not only governs the OER activity but also the reaction mechanism. Specifically, we have shown that lattice oxygen can be activated for the OER and promote new reaction pathways, in addition to the classically studied mechanism on surface metal sites. The OER on oxygen sites can be triggered when the Fermi level becomes pinned to the top of the $\mathrm{O} 2 p$ band for highly covalent oxides, resulting in electronic states near the Fermi level with substantial $\mathrm{O} 2 p$ character. Moreover, OER activities on the RHE scale for perovskites with strong metal-oxygen covalency become higher with increasing $\mathrm{pH}$, indicating that non-concerted protonelectron transfer steps are coupled to the activation of lattice oxygen redox reactions. These new insights open new possibilities for developing highly active catalysts using lattice oxygen redox processes and non-concerted proton-electron transfer steps, bypassing the design limitations of engineering catalysts under the conventional mechanism, which involves only concerted proton-electron transfer steps on surface metal ion sites.

\section{Methods}

Synthesis and bulk characterization. Perovskite $\mathrm{La}_{1-x} \mathrm{Sr}_{x} \mathrm{CoO}_{3-\delta}(x=0,0.5$ and 1$)$ and $\mathrm{Pr}_{0.5} \mathrm{Ba}_{0.5} \mathrm{CoO}_{3-\delta}$ were synthesized by a conventional solid-state route ${ }^{15,19}$. All catalysts reported in this study are single-phase, as analysed by X-ray diffraction (XRD), with lattice parameters consistent with those reported previously (Supplementary Table 1). XRD measurements were performed using a PANalytical X'Pert Pro powder diffractometer in the Bragg-Brentano geometry using copper $\mathrm{K}_{\alpha}$ radiation, and data were collected using the X'Celerator detector in the $8-80^{\circ}$ window in the $2 \theta$ range. The specific surface area of each oxide sample was determined using Brunauer, Emmet and Teller (BET) analysis on a Quantachrome ChemBET Pulsar from single-point BET analysis performed after $12 \mathrm{~h}$ outgassing at $150{ }^{\circ} \mathrm{C}$ (Supplementary Table 2). More details are provided in the Supplementary Information.

Electrochemical measurements of OER activities. Electrodes used for CV and galvanostatic measurements were prepared by drop-casting ink containing oxide catalyst powder on a glassy carbon electrode (GCE), as described previously ${ }^{49}$. The glassy carbon electrode surface $(5 \mathrm{~mm}$ diameter) was loaded with $0.25 \mathrm{mg}_{\text {oxide }} \mathrm{cm}_{\text {disk }}^{-2}$ and a mass ratio of 5:1:1 of oxide catalyst:acetylene black carbon: Nafion. We used an oxide:carbon mass ratio of 5:1 for the OER measurements, as the specific OER activity estimated for oxide particles from such measurements agrees well with that measured from well-defined epitaxial oxide thin-film surfaces of comparable oxide chemistry ${ }^{48}$. Electrochemical measurements were performed with a rotating disk electrode set-up using a glass electrochemical cell with $\mathrm{Ag} / \mathrm{AgCl}$ reference electrode and $\mathrm{Pt}$ counter electrode. The potential was controlled using a Biologic VSP-300 potentiostat. Ohmic losses were corrected by subtracting the ohmic voltage drop from the measured potential, using the electrolyte resistance determined by high-frequency a.c. impedance, where $i R$-corrected potentials are denoted as $E-i R$ ( $i$ as the current and $R$ as the electrolyte resistance). Rotating ring disk electrode (RRDE) measurements were performed on a GCE disk and a Pt ring held at $0.4 \mathrm{~V}$ versus RHE. RRDE measurements of $\mathrm{SrCoO}_{3-\delta}$ in Ar-saturated $1 \mathrm{M} \mathrm{KOH}$ (Supplementary Fig. 17) revealed that oxygen was detected only at potentials higher than $\sim 1.5 \mathrm{~V}$ versus RHE and thus the currents measured at lower potentials are not related to OER but rather to oxygen intercalation upon oxidation of $\mathrm{SrCoO}_{3-\delta}$ (that is, filling of oxygen vacancies in the oxide). More details are provided in the Supplementary Information.

Online electrochemical mass spectroscopy. OLEMS experiment $\mathrm{s}^{50}$ were performed using an EvoLution mass spectrometer system (European Spectrometry Systems). Volatile reaction products were collected from the electrode interface by a small inlet tip positioned close $(\sim 10 \mu \mathrm{m})$ to the electrode surface using a micrometric screw system and a camera. More details are provided in the Supplementary Information. The electrochemical cell used for these experiments is a two-compartment cell with three electrodes, with a gold wire as counter electrode and a reversible hydrogen electrode as the reference electrode. The working electrode was prepared in a comparable manner to that used for OER activity measurements but on a gold disk electrode (4.6 mm diameter) and with an oxide loading of $0.25 \mathrm{mg}_{\text {oxide }} \mathrm{cm}_{\text {disk }}^{-2}$ with no carbon. We used oxide-only electrodes on Au in the OLEMS measurements to avoid any corrosion currents associated with carbon such as oxidization of carbon to form $\mathrm{CO}$ and $\mathrm{CO}_{2}$, as shown previously ${ }^{51,52}$. The OER activities measured for OLEMS measurements without $i R$ correction were in good agreement with those from RDE measurements with $i R$ correction (Supplementary Fig. 2). Moreover, the gold electrode was shown to have no OER activity within the potential range used for the OLEMS measurements (Supplementary Fig. 18). Pristine electrodes were oxidized for $10 \mathrm{~min}$ in $0.1 \mathrm{M} \mathrm{KOH}$ made with ${ }^{18} \mathrm{O}$-labelled water (GMP standard from CMR, $98 \%{ }^{18} \mathrm{O}$ ) at $1.6 \mathrm{~V}$ versus gold counter electrode (no gas bubbling), to label them with ${ }^{18} \mathrm{O}\left({ }^{18} \mathrm{O}\right.$ labelling currents are provided in Supplementary Fig. 19). Electrodes were then rinsed with ${ }^{16} \mathrm{O}$ water to remove $\mathrm{H}_{2}{ }^{18} \mathrm{O}$ and measured in $0.1 \mathrm{M}$ $\mathrm{KOH}$ solution of $\mathrm{H}_{2}{ }^{16} \mathrm{O}$ at $2 \mathrm{mV} \mathrm{s}^{-1}$ for two cycles (no gas bubbling). Because samples were rinsed with ${ }^{16} \mathrm{O}$ water after ${ }^{18} \mathrm{O}$-labelling, it is unlikely that ${ }^{18} \mathrm{O}$ species (for example, $\mathrm{OH}^{*}$ or $\mathrm{H}_{2} \mathrm{O}$ ) adsorbed on the oxide surface contributed substantially to the observed ${ }^{16} \mathrm{O}^{18} \mathrm{O}$ or ${ }^{18} \mathrm{O}^{18} \mathrm{O}$ signal, especially for oxides with a high Co oxidation state. $\mathrm{Ba}_{0.5} \mathrm{Sr}_{0.5} \mathrm{Co}_{0.8} \mathrm{Fe}_{0.2} \mathrm{O}_{3-\delta}$, which transforms amorphous cobalt-ironcontaining oxyhydroxides in bulk during OER ${ }^{36,37}$, had markedly different OLEMS data (Supplementary Fig. 1) from $\mathrm{LaCoO}_{3}, \mathrm{La}_{0.5} \mathrm{Sr}_{0.5} \mathrm{CoO}_{3-\delta}, \mathrm{Pr}_{0.5} \mathrm{Ba}_{0.5} \mathrm{CoO}_{3-\delta}$ and $\mathrm{SrCoO}_{3-\delta}$ particles, which remained stable upon $\mathrm{OER}^{19,40} . \mathrm{Ba}_{0.5} \mathrm{Sr}_{0.5} \mathrm{Co}_{0.8} \mathrm{Fe}_{0.2} \mathrm{O}_{3-\delta}$ had monotonically increasing lattice oxygen $\left({ }^{18} \mathrm{O}^{18} \mathrm{O}\right)$ signals in the positive-going and negative-going scans, confirming bulk oxide decomposition. Moreover, the tip in the open OLEMS set-up used in this study detects ${ }^{32} \mathrm{O}_{2}$ not only from OER but also from the atmosphere. This contribution from the atmosphere in the ${ }^{32} \mathrm{O}_{2}$ detected is evident from Supplementary Table 3, where the amount of ${ }^{32} \mathrm{O}_{2}$ is nearly identical for all four oxides studied. We therefore chose not to include ${ }^{32} \mathrm{O}_{2}$ data in Fig. 2. Each oxide was examined by OLEMS measurements of two to four different electrodes, and the results of different electrodes were comparable, generating error bars for OLEMS data analysis such as the ${ }^{18} \mathrm{O} /{ }^{16} \mathrm{O}$ ratio in Supplementary Figs 4 and 5 and Supplementary Table 3. Multiple OLEMS measurements of $\mathrm{SrCoO}_{3-\delta}$ (Supplementary Fig. 20) and $\mathrm{Ba}_{0.5} \mathrm{Sr}_{0.5} \mathrm{Co}_{0.8} \mathrm{Fe}_{0.2} \mathrm{O}_{3-\delta}$ (Supplementary Fig. 3) are provided in the Supplementary Information as examples.

DFT studies. DFT calculations with Hubbard $U\left(U_{\text {eff }}=3.3 \mathrm{eV}\right)$ correction $^{20,53}$ for the Co $3 d$ electrons were performed with the Vienna Ab-initio Simulation Package $(\text { VASP })^{54,55}$ using the projector-augmented plane-wave method ${ }^{56}$. Exchangecorrelation was treated in the Perdew-Wang-91 generalized gradient approximation $(\mathrm{GGA})^{57}$. Fully relaxed stoichiometric bulk perovskite calculations were simulated with $2 \times 2 \times 2$ perovskite supercells. The double perovskites were simulated based on the reported ordered structures within the $2 \times 2 \times 2$ perovskite supercell. Both $\mathrm{O} 2 p$-band and metal $3 d$-band centres were determined by taking the weighted mean energy of the projected density of states of $\mathrm{O} 2 p$ and metal $3 d$ states (both occupied 
and unoccupied states) relative to the Fermi level. We used a symmetric slab cut along the (001) direction as a model for the (001) $\mathrm{MO}_{2}$ terminated surface and $(2 \times 2)$ surface supercells. The thermodynamic approaches for calculating the OER free energy profiles are described in ref. 44. For more details see Supplementary Information.

Data availability. The original data for Figs $1-5$ in this manuscript are available from https://figshare.com/s/286742731dfc47a8f1c1. Other data sets generated during and/or analysed during the current study are available from the corresponding author on reasonable request.

Received 3 August 2016; accepted 14 November 2016; published online 9 January 2017; addendum published after print 23 June 2017

\section{References}

1. Grimaud, A., Hong, W. T., Shao-Horn, Y. \& Tarascon, J. M. Anionic redox processes for electrochemical devices. Nat. Mater. 15, 121-126 (2016).

2. Lewis, N. S. \& Nocera, D. G. Powering the planet: chemical challenges in solar energy utilization. Proc. Natl Acad. Sci. USA 103, 15729-15735 (2006).

3. Gray, H. B. Powering the planet with solar fuel. Nat. Chem. 1, 7 (2009).

4. Seger, B. et al. 2-Photon tandem device for water splitting: comparing photocathode first versus photoanode first designs. Energy Environ. Sci. 7, 2397-2413 (2014).

5. Hansen, O., Seger, B., Vesborg, P. C. K. \& Chorkendorff, I. A quick look at how photoelectrodes work. Science 350, 1030-1031 (2015).

6. Castelli, I. E. et al. New cubic perovskites for one- and two-photon water splitting using the computational materials repository. Energy Environ. Sci. 5, 9034-9043 (2012).

7. Risch, M. et al. $\mathrm{La}_{0.8} \mathrm{Sr}_{0.2} \mathrm{MnO}_{3-\delta}$ decorated with $\mathrm{Ba}_{0.5} \mathrm{Sr}_{0.5} \mathrm{Co}_{0.8} \mathrm{Fe}_{0.2} \mathrm{O}_{3-\delta}$ : a bifunctional surface for oxygen electrocatalysis with enhanced stability and activity. J. Am. Chem. Soc. 136, 5229-5232 (2014).

8. Jung, J.-I. et al. Optimizing nanoparticle perovskite for bifunctional oxygen electrocatalysis. Energy Environ. Sci. 9, 176-183 (2016).

9. McCalla, E. et al. Visualization of $\mathrm{O}-\mathrm{O}$ peroxo-like dimers in high-capacity layered oxides for Li-ion batteries. Science 350, 1516-1521 (2015).

10. Sathiya, M. et al. Reversible anionic redox chemistry in high-capacity layered-oxide electrodes. Nat. Mater. 12, 827-835 (2013).

11. Man, I. C. et al. Universality in oxygen evolution electrocatalysis on oxide surfaces. Chem. Catal. Chem. 3, 1159-1165 (2011).

12. Rossmeisl, J., Qu, Z. W., Zhu, H., Kroes, G. J. \& Nørskov, J. K. Electrolysis of water on oxide surfaces. J. Electroanal. Chem. 607, 83-89 (2007).

13. Nørskov, J. K. et al. Origin of the overpotential for oxygen reduction at a fuel-cell cathode. J. Phys. Chem. B 108, 17886-17892 (2004).

14. Koper, M. T. M. Theory of multiple proton-electron transfer reactions and its implications for electrocatalysis. Chem. Sci. 4, 2710-2723 (2013).

15. Suntivich, J., May, K. J., Gasteiger, H. A., Goodenough, J. B. \& Shao-Horn, Y. A perovskite oxide optimized for oxygen evolution catalysis from molecular orbital principles. Science 334, 1383-1385 (2011).

16. Matsumoto, Y., Manabe, H. \& Sato, E. Oxygen evolution on $\mathrm{La}_{1-x} \mathrm{Sr}_{x} \mathrm{CoO}_{3}$ electrodes in alkaline solutions. J. Electrochem. Soc. 127, 811-814 (1980).

17. Giordano, L. et al. $\mathrm{pH}$ dependence of OER activity of oxides: current and future perspectives. Catal. Today 262, 2-10 (2016).

18. Trześniewski, B. J. et al. In situ observation of active oxygen species in Fe-containing Ni-based oxygen evolution catalysts: the effect of $\mathrm{pH}$ on electrochemical activity. J. Am. Chem. Soc. 137, 15112-15121 (2015).

19. Grimaud, A. et al. Double perovskites as a family of highly active catalysts for oxygen evolution in alkaline solution. Nat. Commun. 4, 2439 (2013).

20. Lee, Y.-L., Kleis, J., Rossmeisl, J., Shao-Horn, Y. \& Morgan, D. Prediction of solid oxide fuel cell cathode activity with first-principles descriptors. Energy Environ. Sci. 4, 3966-3970 (2011).

21. Suntivich, J. et al. Estimating hybridization of transition metal and oxygen states in perovskites from O K-edge X-ray absorption spectroscopy. J. Phys. Chem. C 118, 1856-1863 (2014).

22. Calle-Vallejo, F., Díaz-Morales, O. A., Kolb, M. J. \& Koper, M. T. M. Why is bulk thermochemistry a good descriptor for the electrocatalytic activity of transition metal oxides? ACS Catal. 5, 869-873 (2015).

23. Rong, X., Parolin, J. \& Kolpak, A. M. A fundamental relationship between reaction mechanism and stability in metal oxide catalysts for oxygen evolution. ACS Catal. 6, 1153-1158 (2016).

24. Hibbert, D. B. \& Churchill, C. R. Kinetics of the electrochemical evolution of isotopically enriched gases. Part 2. $-{ }^{18} \mathrm{O}^{16} \mathrm{O}$ evolution on $\mathrm{NiCo}_{2} \mathrm{O}_{4}$ and $\mathrm{Li}_{\mathrm{x}} \mathrm{Co}_{3-x} \mathrm{O}_{4}$ in alkaline solution. J. Chem. Soc. Faraday Trans. I 80, 1965-1975 (1984).

25. Fierro, S., Nagel, T., Baltruschat, H. \& Comninellis, C. Investigation of the oxygen evolution reaction on $\mathrm{Ti} / \mathrm{IrO}_{2}$ electrodes using isotope labelling and on-line mass spectrometry. Electrochem. Commun. 9, 1969-1974 (2007).
26. Macounova, K., Makarova, M. \& Krtil, P. Oxygen evolution on nanocrystalline $\mathrm{RuO}_{2}$ and $\mathrm{Ru}_{0.9} \mathrm{Ni}_{0.1} \mathrm{O}_{2-\delta}$ electrodes-DEMS approach to reaction mechanism determination. Electrochem. Commun. 11, 1865-1868 (2009).

27. Wohlfahrt-Mehrens, M. \& Heitbaum, J. Oxygen evolution on $\mathrm{Ru}$ and $\mathrm{RuO}_{2}$ electrodes studied using isotope labelling and on-line mass spectrometry. J. Electroanal. Chem. Interf. Electrochem. 237, 251-260 (1987).

28. Surendranath, Y., Kanan, M. W. \& Nocera, D. G. Mechanistic studies of the oxygen evolution reaction by a cobalt-phosphate catalyst at neutral pH. J. Am. Chem. Soc. 132, 16501-16509 (2010).

29. Mavros, M. G. et al. What can density functional theory tell us about artificial catalytic water splitting? Inorg. Chem. 53, 6386-6397 (2014).

30. Wang, L.-P. \& Van Voorhis, T. Direct-coupling $\mathrm{O}_{2}$ bond forming a pathway in cobalt oxide water oxidation catalysts. J. Phys. Chem. Lett. 2, 2200-2204 (2011).

31. Betley, T. A., Wu, Q., Van Voorhis, T. \& Nocera, D. G. Electronic design criteria for O-O bond formation via metal-oxo complexes. Inorg. Chem. 47, 1849-1861 (2008).

32. Cheng, $\mathrm{X}$. et al. Oxygen evolution reaction on $\mathrm{La}_{1-x} \mathrm{Sr}_{x} \mathrm{CoO}_{3}$ perovskites: a combined experimental and theoretical study of their structural, electronic, and electrochemical properties. Chem. Mater. 27, 7662-7672 (2015).

33. Goodenough, J. B. Perspective on engineering transition-metal oxides. Chem. Mater. 26, 820-829 (2014).

34. Rouxel, J. Anion-cation redox competition and the formation of new compounds in highly covalent systems. Chem. Eur. J. 2, 1053-1059 (1996).

35. Nücker, N., Fink, J., Fuggle, J. C., Durham, P. J. \& Temmerman, W. M. Evidence for holes on oxygen sites in the high- $T_{c}$ superconductors $\mathrm{La}_{2-x} \mathrm{Sr}_{x} \mathrm{CuO}_{4}$ and $\mathrm{YBa}_{2} \mathrm{Cu}_{3} \mathrm{O}_{7-y}$. Phys. Rev. B 37, 5158-5163 (1988).

36. Amatucci, G. G., Tarascon, J. M. \& Klein, L. C. $\mathrm{CoO}_{2}$, the end member of the $\mathrm{Li} x \mathrm{CoO}_{2}$ solid solution. J. Electrochem. Soc. 143, 1114-1123 (1996).

37. Mefford, J. T., Hardin, W. G., Dai, S., Johnston, K. P. \& Stevenson, K. J. Anion charge storage through oxygen intercalation in $\mathrm{LaMnO}_{3}$ perovskite pseudocapacitor electrodes. Nat. Mater. 13, 726-732 (2014).

38. Nemudry, A., Goldberg, E. L., Aguirre, M. \& Alario-Franco, M. A. Electrochemical topotactic oxidation of nonstoichiometric perovskites at ambient temperature. Solid State Sci. 4, 677-690 (2002).

39. Grenier, J. C. et al. Electrochemical oxygen intercalation into oxide networks. J. Solid State Chem. 96, 20-30 (1992).

40. May, K. J. et al. Influence of oxygen evolution during water oxidation on the surface of perovskite oxide catalysts. J. Phys. Chem. Lett 3, 3264-3270 (2012).

41. Risch, M. et al. Structural changes of cobalt-based perovskites upon water oxidation investigated by EXAFS. J. Phys. Chem. C 117, 8628-8635 (2013).

42. Binninger, T. et al. Thermodynamic explanation of the universal correlation between oxygen evolution activity and corrosion of oxide catalysts. Sci. Rep. 5, 12167 (2015).

43. Kim, J., Yin, X., Tsao, K.-C., Fang, S. \& Yang, H. $\mathrm{Ca}_{2} \mathrm{Mn}_{2} \mathrm{O}_{5}$ as oxygen-deficient perovskite ellectrocatalyst for oxygen evolution reaction. J. Am. Chem. Soc. 136, 14646-14649 (2014)

44. Lee, Y.-L., Gadre, M. J., Shao-Horn, Y. \& Morgan, D. Ab initio GGA+U study of oxygen evolution and oxygen reduction electrocatalysis on the (001) surfaces of lanthanum transition metal perovskites $\mathrm{LaBO}_{3}(\mathrm{~B}=\mathrm{Cr}, \mathrm{Mn}, \mathrm{Fe}, \mathrm{Co}$ and $\mathrm{Ni})$. Phys. Chem. Chem. Phys. 17, 21643-21663 (2015).

45. Bockris, J. O. M. \& Otagawa, T. The electrocatalysis of oxygen evolution on perovskites. J. Electrochem. Soc. 131, 290-302 (1984).

46. Koper, M. M. Volcano activity relationships for proton-coupled electron transfer reactions in electrocatalysis. Top. Catal. 58, 1153-1158 (2015).

47. Nemudry, A., Rudolf, P. \& Schöllhorn, R. Topotactic electrochemical redox reactions of the defect perovskite $\mathrm{SrCoO}_{2.5+x}$. Chem. Mater. 8, 2232-2238 (1996).

48. Koroidov, S., Anderlund, M. F., Styring, S., Thapper, A. \& Messinger, J. First turnover analysis of water-oxidation catalyzed by Co-oxide nanoparticles. Energy Environ. Sci. 8, 2492-2503 (2015).

49. Suntivich, J., Gasteiger, H. A., Yabuuchi, N. \& Shao-Horn, Y. Electrocatalytic measurement methodology of oxide catalysts using a thin-film rotating disk electrode. J. Electrochem. Soc. 157, B1263-B1268 (2010).

50. Wonders, A. H., Housmans, T. H. M., Rosca, V. \& Koper, M. T. M. On-line mass spectrometry system for measurements at single-crystal electrodes in hanging meniscus configuration. J. Appl. Electrochem. 36, 1215-1221 (2006).

51. Meyers, J. P. \& Darling, R. M. Model of carbon corrosion in PEM fuel cells. J. Electrochem. Soc. 153, A1432-A1442 (2006).

52. He, M., Fic, K., Frckowiak, E., Novak, P. \& Berg, E. J. Ageing phenomena in high-voltage aqueous supercapacitors investigated by in situ gas analysis. Energy Environ. Sci. 9, 623-633 (2016).

53. Lee, Y.-L., Kleis, J., Rossmeisl, J. \& Morgan, D. Ab initio energetics of $\mathrm{LaBO}_{3}(001)(\mathrm{B}=\mathrm{Mn}, \mathrm{Fe}, \mathrm{Co}$, and Ni) for solid oxide fuel cell cathodes. Phys. Rev. B 80, 224101 (2009).

54. Kresse, G. \& Furthmüller, J. Efficient iterative schemes for ab initio total-energy calculations using a plane-wave basis set. Phys. Rev. B 54, 11169-11186 (1996). 
55. Kresse, G. \& Hafner, J. Ab initio molecular dynamics for liquid metals. Phys. Rev. B 47, 558-561 (1993).

56. Blöchl, P. E. Projector augmented-wave method. Phys. Rev. B 50, 17953-17979 (1994).

57. Perdew, J. P. \& Wang, Y. Accurate and simple analytic representation of the electron-gas correlation energy. Phys. Rev. B 45, 13244-13249 (1992).

58. Rossmeisl, J., Logadottir, A. \& Nørskov, J. K. Electrolysis of water on (oxidized) metal surfaces. Chem. Phys. 319, 178-184 (2005).

59. Goodenough, J. B., Manoharan, R. \& Paranthaman, M. Surface protonation and electrochemical activity of oxides in aqueous solution. J. Am. Chem. Soc. 112, 2076-2082 (1990).

\section{Acknowledgements}

This work was supported in part by the Skoltech-MIT Center for Electrochemical Energy, the SMART programme, and the Department of Energy (DOE) and National Energy Technology Laboratory (NETL), Solid State Energy Conversion Alliance (SECA) Core Technology Program (Funding Opportunity Number DEFE0009435). This work is also supported in part by the Netherlands Organization for Scientific Research (NWO) within the research programme of BioSolar Cells, co-financed by the Dutch Ministry of Economic Affairs, Agriculture and Innovation. This research used resources of the National Energy
Research Scientific Computing Center, a DOE Office of Science User Facility supported by the Office of Science of the US Department of Energy (contract no. DE-AC02-05CH11231) The authors would like to acknowledge Dane Morgan and Jean-Marie Tarascon for fruitful discussion.

\section{Author contributions}

Y.S.-H. and A.G. designed the experiments. A.G. and W.T.H. carried out the synthesis, structural and chemical analysis. A.G. and B.H. performed the electrochemical measurements. O.D.-M. and M.T.M.K. conducted the OLEMS measurements. Y.-L.L and L.G. carried out the DFT calculations. Y.S.-H. wrote the manuscript and all authors edited the manuscript.

\section{Additional information}

Supplementary information is available in the online version of the paper. Reprints and permissions information is available online at www.nature.com/reprints. Correspondence and requests for materials should be addressed to Y.S.H.

\section{Competing financial interests}

The authors declare no competing financial interests. 


\section{Addendum: Activating lattice oxygen redox reactions in metal oxides to catalyse oxygen evolution}

Alexis Grimaud, Oscar Diaz-Morales, Binghong Han, Wesley T. Hong, Yueh-Lin Lee, Livia Giordano, Kelsey A. Stoerzinger, Marc T. M. Koper and Yang Shao-Horn

Nature Chemistry 9, 457-465 (2017); published online 09 January 2017; addendum published after print 23 June 2017.

In our Article we reported direct experimental evidence for the involvement of lattice oxygen redox chemistry in the perovskitecatalysed oxygen evolution reaction (OER). We would like to cite an Article ${ }^{1}$ that was published prior to ours that readers should be aware of. The Article reports the OER activities of a series of cobaltite perovskites $\left(\mathrm{La}_{1-x} \mathrm{Sr}_{x} \mathrm{CoO}_{3-\delta}\right)$, and its authors rationalize the high activities for materials with $x>0.4$ through the participation of lattice oxygen in the OER mechanism, a hypothesis that is supported by density functional theory.

\section{References}

1. Mefford, J. T. et al. Water electrolysis on $\mathrm{La}_{1-x} \mathrm{Sr}_{x} \mathrm{CoO}_{3-\delta}$ perovskite electrocatalysts. Nat. Commun. 7, 11053 (2016). 